\title{
Insights into Chemical Dynamics and Their Impact on the Reactivity of Pt Nanoparticles during CO Oxidation by Operando TEM
}

\author{
Milivoj Plodinec, Hannah C. Nerl, Frank Girgsdies, Robert Schlögl, and Thomas Lunkenbein* \\ Cite This: ACS Catal. 2020, 10, 3183-3193 \\ Read Online
}

ACCESS |

Wll Metrics \& More

Article Recommendations

Supporting Information

ABSTRACT: The functionality of heterogeneous catalysts is influenced by a delicate interplay of multiple parameters, including morphology and structure, chemical potential gradients and related dynamics. Here, we report on how these factors are interconnected. Combining time-resolved transmission electron microscopy imaging and selected area electron diffraction with online conversion detection, $\mathrm{CO}$ oxidation over $\mathrm{Pt}$ nanoparticles was studied at a pressure of $700 \mathrm{mbar}$ and temperatures up to $500{ }^{\circ} \mathrm{C}$. The different interactions between reactants and catalysts over the entire range of catalytic conversion were investigated. Chemical dynamics in this reaction were found to consist of both morphological transformations and fluctuating structural dynamics. Morphological transformations were observed mostly in low activity regimes, leading to nanoparticles with increased stable surface facets. Meanwhile structural

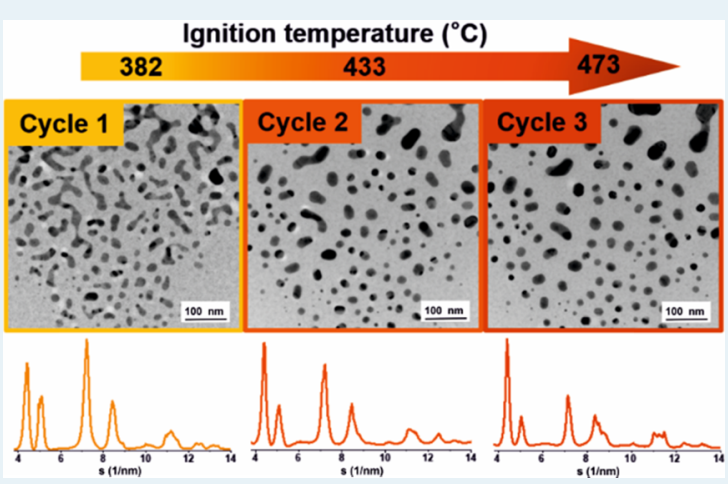
changes were observed during high activity regimes where the partial pressures remained constant. Furthermore, the observed changes were found to occur in both the bulk and the surface of the catalyst. Catalytic cycling revealed that morphological transformations and structural dynamics have different implications on the reactivity and are mostly irreversible.

KEYWORDS: chemical dynamics, operando TEM, Pt nanoparticles, CO oxidation, morphological changes, structural changes

\section{INTRODUCTION}

In the past, the majority of industrially relevant highperformance heterogeneous catalysts were found by empirical optimization rather than by knowledge-based tailoring. ${ }^{1}$ This was due to a lack of evidence-based knowledge about material properties that influence the activity as well as the working structure of catalysts. Even today, the standard approach for assessing the working state of catalysts is to comparatively characterize them ex situ before and after the catalytic reaction. However, heterogeneous catalysts are metastable systems where the nature of the active state depends on the applied chemical potential (i.e., temperature and partial pressures) that can trigger "chemical dynamics"., ${ }^{1,2}$ The term chemical dynamics can be used to describe several scientific aspects. ${ }^{3-8}$ For heterogeneous catalysis, it was recently introduced. ${ }^{7,8}$ Here, we use the term chemical dynamics to describe morphological transformations and structural dynamics which relate to the induced surface and bulk changes of the catalyst. These two contributions of chemical dynamics can have a forcing and a fluctuating character, respectively. ${ }^{8}$ In addition, since the working catalysts are thought to be metastable, the active surfaces could be unstable at noncatalytic conditions, which could lead to the detection of inactive or deactivated structures instead of the active ones, resulting in misinterpretations. Thus, to enhance the current understanding of the functionality of a working catalyst, relevant working conditions have to be applied during structural examination.

The reaction of $\mathrm{CO}$ oxidation is often used as a model reaction and is therefore well-studied. ${ }^{10-12}$ Nevertheless, operando studies to-date based on surface-sensitive X-ray diffraction (XRD), ${ }^{13}$ X-ray photoelectron spectroscopy (XPS), ${ }^{14}$ X-ray absorption spectroscopy (XAS), ${ }^{15-17}$ scanning tunneling microscopy (STM), ${ }^{18,19}$ and vibrational spectrosco$\mathrm{py}^{20}$ have led to contradictory conclusions. So far, there has been no clear consensus on crucial issues such as whether the surface or subsurface Pt oxides are active ${ }^{13,16-19}$ or nonactive ${ }^{15}$ components in the CO oxidation over Pt nanoparticles (NPs). Contradictory results from different studies could be due to differences in composition of the catalytic systems and/or reaction parameters but, more importantly, to a general lack of local information on the origin of chemical dynamics triggering the catalytic activity. This absence of spatially resolved nanoscale information is inherent to all the techniques described above. Temporally and spatially resolved operando transmission electron microscopy (TEM) is the only technique

Received: August 28, 2019

Revised: January 31, 2020 
a)

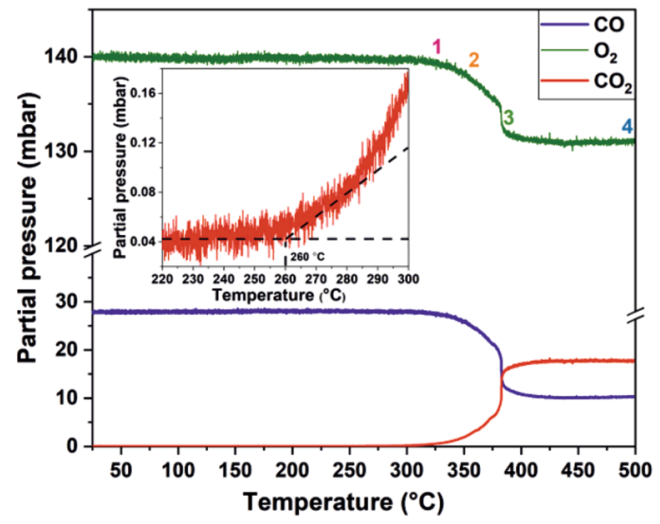

1

c)

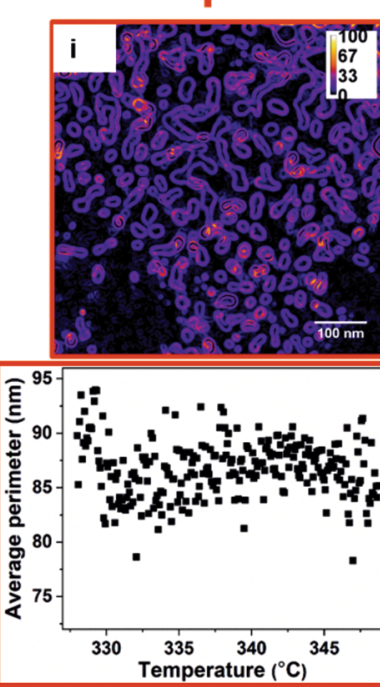

b)

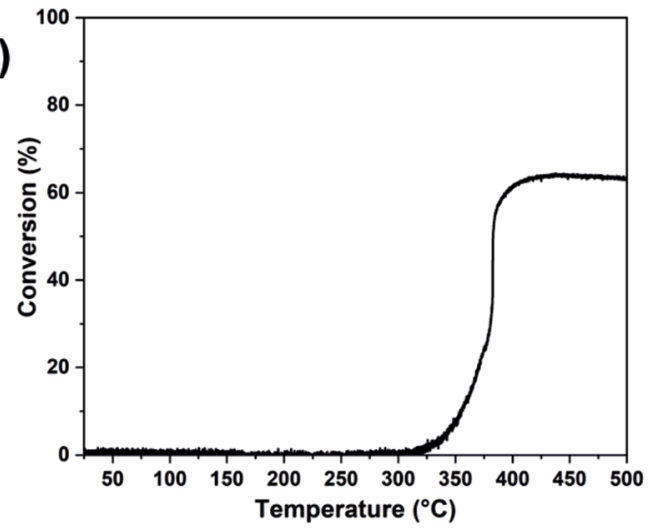

3
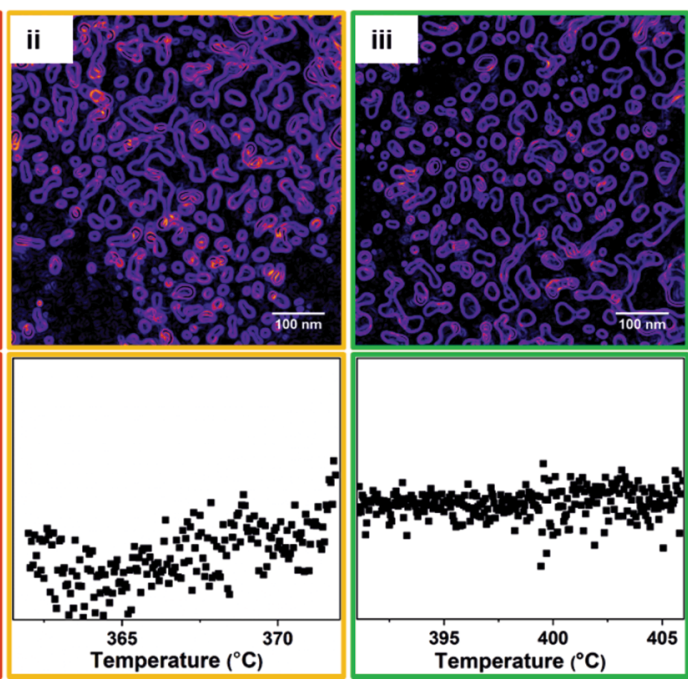

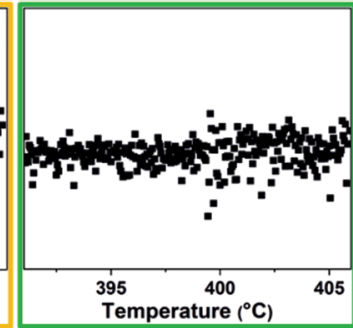

4

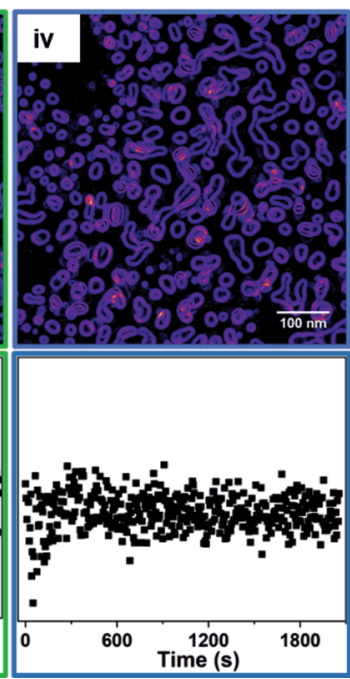

Figure 1. Operando TEM measurements. (a) Online MS data for CO oxidation over Pt NPs heated from room temperature (RT) to $500{ }^{\circ} \mathrm{C}$ (first cycle) obtained from the operando TEM experiment. The inset in panel (a) shows the onset of $\mathrm{CO}_{2}$ production. The intersection of two dotted lines in the $\mathrm{CO}_{2}$ signal denotes the onset temperature. (b) $\mathrm{CO}$ conversion as function of the temperature. (c) Particle shape analysis with corresponding average perimeter distribution of NPs at different temperature regimes: (i) $328-348{ }^{\circ} \mathrm{C}$, (ii) $362-372{ }^{\circ} \mathrm{C}$, (iii) $391-406{ }^{\circ} \mathrm{C}$, and (iv) isothermal treatment at $500{ }^{\circ} \mathrm{C}$. The color intensity bar in the top right corner of the first image represents shape changes of the Pt NPs for all standard deviation (STD) images: white/yellow/orange/red represents regions exhibiting greater shape change versus purple/blue/black regions that showed little to no change. Pt NPs were found to change shape in the first cycle in the low activity regimes 1 (red) and 2 (yellow) corresponding to the regions denoted in panel (a) compared to the high activity regimes 3 (green) and 4 (blue). Reaction conditions: temperature ramp, $1{ }^{\circ} \mathrm{C} / \mathrm{min}$; pressure, $700 \mathrm{mbar}$; flow rate, $20 \mu \mathrm{L} / \mathrm{min}$; gas feed, $\mathrm{CO}: \mathrm{O}_{2}: \mathrm{He}=1: 5: 19$; and beam dose rate, below 30 e/ $\AA^{2} \mathrm{~s}$.

to provide high-resolution information about the structurefunction relationship under relevant working conditions and to visualize intermediate states at the atomistic level. ${ }^{21,22}$ Such a pioneering TEM work has, for instance, been accomplished by Vendelbo et al. who visualized the oscillatory behavior of $\mathrm{Pt}$ nanoparticles during $\mathrm{CO}$ oxidation. ${ }^{21}$ However, oscillatory phenomena are based on nonlinear dynamics, and therefore, their study alone cannot provide the complete catalytic picture. In this present study, the different interactions between reactants and catalysts over the entire range of catalytic conversions were investigated. Several ex situ and in situ TEM and HRTEM studies have reported on morphological and structural changes of $\mathrm{Pt}$ nanoparticles induced by different gaseous environments and temperatures. ${ }^{20,21,23-30}$ For instance, the reshaping and facetting of $\mathrm{Pt}$ nanoparticles during thermal treatment in different reductive and oxidative environments have been observed. Thermal treatment in $\mathrm{H}_{2}{ }^{20,23,25-28} \mathrm{CO},{ }^{21,24,25,29}$ or vacuum ${ }^{24,25}$ have been shown to lead to more facetted particles with the dominant $\operatorname{Pt}(111)$,
$\mathrm{Pt}(100)$, and $\mathrm{Pt}(110)$ facets. Meanwhile, more oxidative conditions such as $\mathrm{O}_{2} / \mathrm{N}_{2},{ }^{26} \mathrm{NO}_{x}{ }^{24}$ or $\mathrm{O}_{2}{ }^{23,26}$ have been shown to lead to particles with more spherical shapes with higher amounts of exposed higher order facets.

Using a homebuilt time-resolved TEM setup that is directly coupled to a quadrupole mass spectrometer (QMS) for gas analysis, which allows online conversion detection, ${ }^{31}$ we are able to begin to untangle chemical dynamics. Using this operando TEM approach, we combine imaging and selected area electron diffraction (SAED) analysis with monitoring of the catalytic activity over time to directly study the structurefunction relationship of Pt NPs during $\mathrm{CO}$ oxidation in different activity regimes. Using this combination of spatially resolved morphological and structural information correlated to the catalytic activity, we are able to untangle different contributions from chemical dynamics to the reaction. Here, we will show that we can distinguish between two aspects of chemical dynamics: morphological transformations and structural dynamics. It will also be shown that morphological 

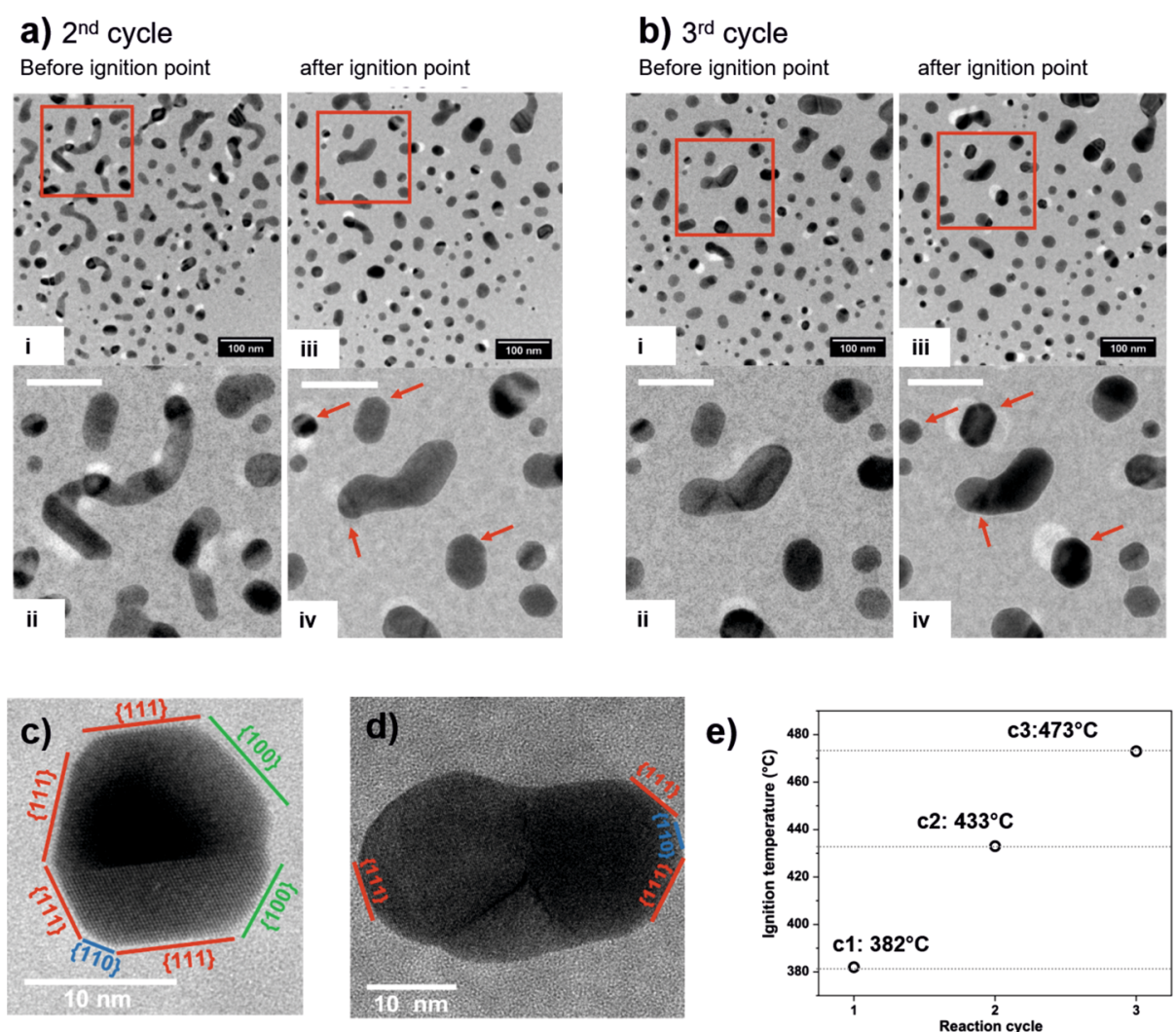

Figure 2. Morphological changes of Pt NPs when comparing different activity regimes in the (a, c) second and (b, d) third catalytic cycle before and after the ignition point. (a) TEM images from the second cycle: (i, ii) at 250 and (iii, iv) at $450{ }^{\circ} \mathrm{C}$. (ii, iv) Higher magnification images of the region of interest marked by red squares in (i) and (iii), respectively. (b) TEM images from the third cycle: (i, ii) at 200 and (iii, iv) at $493{ }^{\circ} \mathrm{C}$. (ii, iv) Higher magnification images of the region of interest marked by red squares in (i) and (iii), respectively. (c) Formation of low index facets of Pt NPs after the second cycle: high-resolution TEM image of a twinned Pt NP viewed along [01-1] (imaged after cooling to $200{ }^{\circ} \mathrm{C}$ ). (d) Low index facets of Pt NPs during the third cycle: high-resolution TEM image of a twinned Pt NP (imaged at $460{ }^{\circ} \mathrm{C}$ ). (e) Increase of the ignition temperature during catalytic cycling. Red arrows denote Pt NPs with more pronounced faceting after the third cycle compared to the second cycle. Reaction conditions: temperature ramp, $1{ }^{\circ} \mathrm{C} / \mathrm{min}$; pressure, $700 \mathrm{mbar}$; flow rate, $20 \mu \mathrm{L} / \mathrm{min}$; gas feed, CO:O $: \mathrm{He}=1: 5: 19$; beam dose rates: (a, b) $<30 \mathrm{e} / \AA^{2}$ s. (c) $700 \mathrm{e} / \AA^{2} \mathrm{~s}$ and (d) $<1000 \mathrm{e} / \AA^{2}$ s. (Scale bars in panels (a-ii,iv) and (b-ii,iv), $50 \mathrm{~nm}$ ).

transformations are dominantly caused by initial gradients of the involved partial pressures and that they lead to the formation of flat surfaces. Structural dynamics, in contrast, were found to be induced by reactant diffusion through the bulk and have a fluctuating character. Furthermore, morphological and structural changes were found to occur at different activity levels. We further assessed the effects of reaction cycling on morphology and structure of the Pt NPs as well as their implications on reactivity.

\section{RESULTS}

2.1. Morphological Changes during $\mathrm{CO}$ Oxidation over Pt NPs. The morphological and structural evolution of the Pt NPs (see the Materials and Methods section as well as Figure S1 for details on the in situ synthesis) were studied operando in the $\mathrm{CO}$ oxidation under relevant reaction conditions. Any changes in the Pt NPs that were observed using TEM imaging and electron diffraction were correlated with the different activity states.

The reaction was found to light off at $260{ }^{\circ} \mathrm{C}$ as indicated by an increase in the $\mathrm{CO}_{2}$ signal in the QMS (Figure 1a, inset). This is in line with previous operando studies on Pt NPs that were deposited on TEM windows. ${ }^{21,32}$ Simultaneously, the signals arising from $\mathrm{CO}$ and $\mathrm{O}_{2}$ decreased. At $382{ }^{\circ} \mathrm{C}$, the reaction ignited as indicated by the sharp increase of the $\mathrm{CO}_{2}$ signal (Figure 1a). This ignition of the reaction could also be followed by extracting the calorimetric data where at the same temperature and exothermic event could be observed (Figure S2). At $425{ }^{\circ} \mathrm{C}$, the reaction levelled off at a $\mathrm{CO}$ conversion of $63 \%$ (Figure $1 \mathrm{~b}$ ). The conversion was thought to be probably limited by transport effects in the kinetically different reactor geometry compared to fixed bed reactors. In addition, mass transfer limitation, where the high $\mathrm{CO}_{2}$ concentration around the Pt NP surface forming a boundary layer, could prevent further $\mathrm{CO}$ diffusion to the catalyst surface. ${ }^{33,34}$ At $500{ }^{\circ} \mathrm{C}$, isothermal treatment for $\sim 0.5 \mathrm{~h}$ was performed, which led to a deactivation of $\sim 2.3 \%$ (Figure S3). Blank experiments using only the MEMS-based gas cell TEM holder showed no CO conversion at temperatures up to $500{ }^{\circ} \mathrm{C}$, proving that the cell itself was not causing any conversion during the real catalytic reaction and that gas phase reactions were absent (Figure S4).

During the temperature ramping and isothermal treatment at $500{ }^{\circ} \mathrm{C}$, experiments that focused on morphological and structural changes were performed simultaneously. Multiple series of TEM images and SAED patterns were acquired. The series of micrographs acquired during the activation phase of the catalyst (regime $1,328-348{ }^{\circ} \mathrm{C}$; regime $2,362-372{ }^{\circ} \mathrm{C}$; Figure 1a) show the transformation from elongated to more spherical homogeneous particles during the reaction (Videos S1 and S2). Furthermore, in the first cycle, smaller particles 

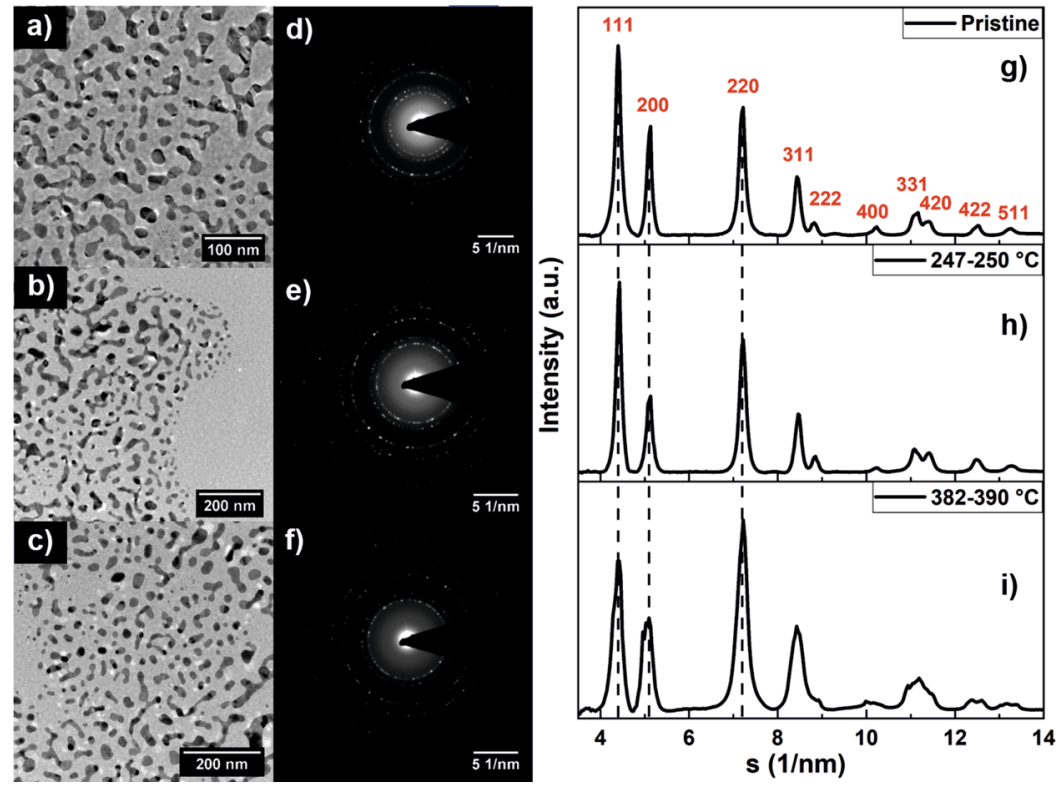

Figure 3. Structural changes of the Pt NPs during the first cycle. SAED analysis at different reaction conditions: $(\mathrm{a}, \mathrm{d}, \mathrm{g})$ at $400{ }^{\circ} \mathrm{C}$ in synthetic air $\left(20 \% \mathrm{O}_{2}\right.$ in $\left.\mathrm{He}\right)$; flow rate, $20 \mu \mathrm{L} / \mathrm{min}$; pressure, 720 mbar. (b, e, h) at $247-250{ }^{\circ} \mathrm{C}$; (c, f, i) at $382-390{ }^{\circ} \mathrm{C}$. (a-c) TEM images showing the dispersed Pt NPs on the support film, corresponding to the regions of interest where $(d-f)$ SAED patterns were acquired and from which ( $g-i)$ averaged radial profiles were extracted. Changes in shape and position of reflections that correspond to the (111), (200), and (220) lattice planes are marked with dashed lines. Reaction conditions for panels (b), (e), (h), (c), (f), and (i): temperature ramp, $1{ }^{\circ} \mathrm{C} / \mathrm{min}$; pressure, $700 \mathrm{mbar}$; flow rate, $20 \mu \mathrm{L} / \mathrm{min}$; gas feed, $\mathrm{CO}: \mathrm{O}_{2}: \mathrm{He}=1: 5: 19$.

$(2-20 \mathrm{~nm})$ exhibited faster morphological transformation than larger ones, which appeared to be static in comparison (Videos S1 and S2). In addition, splitting of Pt NPs was also observed (Videos S1 and S2). However, there was no indication of sintering of Pt NPs. At high conversion and during isothermal treatment (regime 3, 391-406 ${ }^{\circ} \mathrm{C}$; regime 4, $500{ }^{\circ} \mathrm{C}$; Figure 1a), the fraction of Pt NPs that exhibited only small to no morphological changes was found to be large (Videos S3 and S4).

Standard deviation (STD) analysis of the image contrast from the operando videos was done to assess relative changes in the shape and average perimeter of the Pt NPs (Figure 1c). Morphological transformations of the Pt NPs were found to be more pronounced in the low activity regimes 1 and 2 , before the ignition point (Figure 1c-i,ii), compared to the high activity after the ignition point in regimes 3 and 4 (Figure 1c-iii,iv). In addition, the average perimeter of the Pt NPs was found to have a broader distribution in the low activity regimes (Figure 1c-i,ii) compared to the high activity regimes (Figure 1c-iii,iv). This operando observation strongly suggests that Pt NPs in the $\mathrm{CO}$ oxidation reaction undergo more pronounced morphological changes in the low activity regime; that is, the regime in which the gradient of $\mathrm{CO}$ partial pressure is significantly higher, rather than in the high activity regime, where the $\mathrm{CO}$ partial pressure is low.

2.2. Morphology of Pt NPs during Reaction Cycling. Similar morphological transformations compared to the first cycle were observed in the second (Figure 2a) and third (Figure $2 b$ ) reaction cycle (see Figures S5 and S6 and Videos S5 and S6 for additional images from the second and third cycle acquired at different temperatures). During reaction cycling, the morphologies of the Pt NPs evolved from initially elongated to spherical (Figure 1c and 2a,b and Figures S5 and S6) in the first cycle to more faceted with a progressive number of cycles. The faceted NPs were found to exhibit higher surface proportions of low index terminations, such as $\{111\},\{110\}$, and $\{100\}$, as shown in the images in Figure 2a (iii-iv) and $2 c$ from the second cycle and Figure $2 \mathrm{~b}$ (iii-iv) and $2 \mathrm{~d}$ from the third cycle (see also Figures S5 and S6 for additional images) compared to the particles at the beginning of the second cycle (Figure 2a-i,ii). A high degree of twinning in the bulk of the Pt NPs was also observed (Figure S7). Note that, during reaction cycling, the morphology of the Pt NPs only changed as long as changes of the partial pressures were present during heating. In addition, the activity of the Pt NPs decreased during cycling (Figure 2e and Figures S8a,b-S10a,b). This observation suggests that the convergence of the morphology of the $\mathrm{Pt}$ NPs toward the formation of thermodynamically more stable surface facets is one cause for deactivation. In addition, with the increasing cycle number, the ignition point was found to shift to higher temperatures (Figure 2e). After the ignition point had been reached, oscillations in the MS traces were observed in the second and third cycle (Figures S9 and S10a,b). These oscillations were characterized by nonregular periodicities and amplitudes. They led to a sudden heat release as demonstrated by the calorimetric analysis (Figure S11) due to the exothermicity of the reaction. During this oscillatory behavior, no changes in the morphology of the Pt NPs (Video S7) were observed despite the chemical potential changes rapidly.

Furthermore, morphological changes of the Pt NPs during cooling in the second and third cycle were compared (Figure S12). Changes in the morphology occurred after the second cycle (shown in the TEM images in Figure S12). However, after cooling to room temperature (RT) in the third cycle, the occurrence of morphological changes was drastically reduced. This observation strengthens the view that the morphological aging of the investigated Pt NPs was induced by gradients of the partial pressures, leading to more thermodynamically stable 

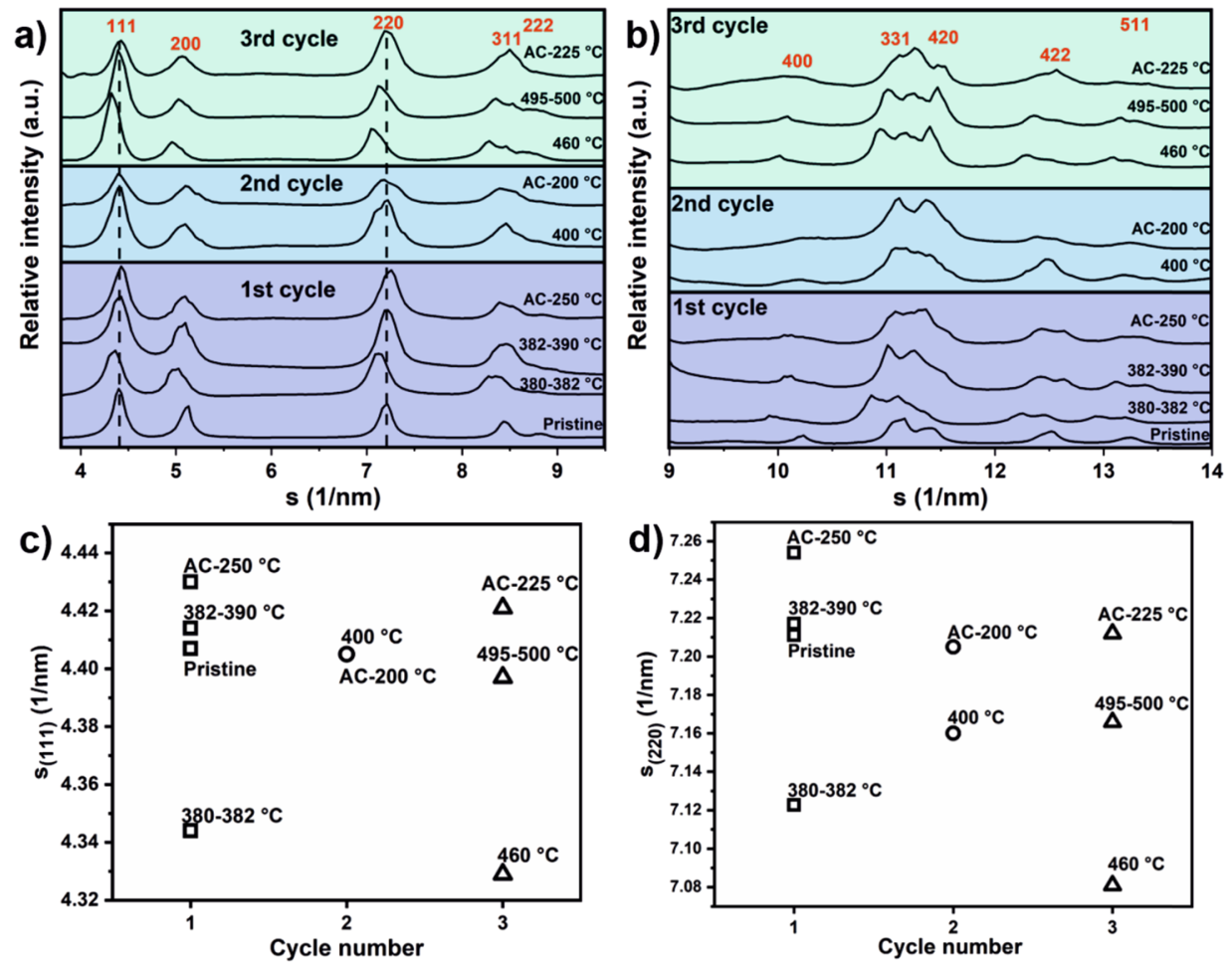

Figure 4. Fluctuations in the SAED patterns for three cycles at different states of reaction. (a) Averaged radial profile distribution of the SAED patterns for lower index planes. (b) Averaged radial profile distribution of SAED patterns for high index planes. (c, d) Highlight fluctuations of the positions of the reflections that correspond to the (111) and (220) lattice planes, respectively. Pristine: SAED patterns of Pt NPs acquired at 400 ${ }^{\circ} \mathrm{C}$ in synthetic air $\left(20 \% \mathrm{O}_{2}\right.$ in $\left.\mathrm{He}\right)$ with a flow rate of $20 \mu \mathrm{L} / \mathrm{min}$ and at a pressure of $720 \mathrm{mbar}$. AC, after cooling. Dotted lines in panel (a) highlight the position shifts of reflections for the (111) and (220) planes. Reaction conditions: temperature ramp, $1^{\circ} \mathrm{C} / \mathrm{min}$; pressure, $700 \mathrm{mbar}$; flow rate, $20 \mu \mathrm{L} / \mathrm{min}$; gas feed, $\mathrm{CO}: \mathrm{O}_{2}: \mathrm{He}=1: 5: 19$.

surface terminations. The morphological changes prove to be irreversible under the conditions of reaction cycling.

\subsection{Structural Changes of the Pt NPs under Reaction} Conditions. Structural changes of the Pt NPs under reaction conditions were tracked with temporally resolved SAED analysis during catalytic cycling. To exclude size effects, different regions that exhibit similar sample amounts and particle size distributions were used. From the regions shown in the TEM images (Figure $3 \mathrm{a}-\mathrm{c}$ ) that correspond to the first cycle, SAED patterns (Figure 3d-f) were recorded and stacked for the desired temperature regimes. From these SAED patterns, averaged radial diffraction profiles (Figure $3 g-i$ ) were extracted. The averaged radial diffraction profiles of the measurement conducted at $400{ }^{\circ} \mathrm{C}$ in synthetic air showed the presence of sharp characteristic diffraction peaks for Pt (Figure $3 \mathrm{~g}$ ). The evolution of the averaged radial diffraction profiles during $\mathrm{CO}$ oxidation in the temperature range between 247$250{ }^{\circ} \mathrm{C}$ showed small changes in the reflection intensities, shape, and full width at half-maximum ( fwhm) (Figure $3 \mathrm{~h}$ ). Between 382 and $390{ }^{\circ} \mathrm{C}$, after the ignition of the reaction (Figure $3 \mathrm{i}$ ), the fwhm of the reflections increased. In this regime, asymmetric reflection profiles and changes in the intensity ratios can also be observed (Figure 3i). These findings suggest that the main structural changes occurred during the short period of ignition.

The structural changes were mostly preserved during reaction and temperature cycling. A comparison of the evolution of the SAED averaged radial profile over three heating and cooling cycles revealed the appearance of additional shoulders that fluctuated between lower or higher values for reflections that correspond to the (111), (200), (220), and (311) lattice planes (Figure 4a and also Figures S8c to $S 10 \mathrm{c})$. In addition, the reflections that correspond to the higher order (331) and (420) lattice planes, which appeared blurred during the reaction, could be partially differentiated again after cooling (Figure $4 \mathrm{~b}$ and also Figures S8c to S10c), while the fwhm remained broad. Additionally, the reflections that correspond to the low index (111) and (220) lattice planes show a nonlinear change of the positions of the reflections with temperature (Figure $4 c, d$ ). These differences in the SAED patterns are caused by changes in the bulk structure.

The observed partial fluctuation of the bulk structure (Figure $4 c, d$ ) combined with the observed asymmetry of the shape of the reflections could indicate a frustrated phase transition. ${ }^{7}$ Note that in situ X-ray diffraction (XRD) patterns did not show any differences between before and after the catalytic reaction (Figure S13 and Table S1) as this technique has too low sensitivity for the local structural changes.

\section{DISCUSSION}

3.1. Catalysis-Induced Changes. In this study, using imaging and electron diffraction, we show for the first time, that changes of the particle shape and bulk structure can be disentangled and correlated to different regimes of the catalytic activity (Figures 1 to 4 and Figures S5-S10).

The local nanoscale information presented here has been inaccessible to-date when employing averaging and integrating techniques to study this system. The relevance to catalytic activity of the changes observed in morphology and structure 
was further verified by the simultaneous observation of performance and heat flux. Although many in situ TEM studies have already revealed insights into the structure and shape changes of different functional materials, including $\mathrm{MoS}^{35} \mathrm{Co},{ }^{36,37} \mathrm{Ag}^{38} \mathrm{Cu}^{2,39} \mathrm{Pt}^{21,23}$ or $\mathrm{PdZn}$ alloys ${ }^{40}$ in different reductive and oxidative environments, a direct proof of its catalytic relevance has only been shown once. ${ }^{21}$ The author showed an oscillatory behavior in the reaction traces and attributed it to a periodic reshaping of the Pt NPs. This indeed is a fundamental achievement in catalysis research; however, it does not allow to establish detailed structureactivity correlations as essential information on activation, steady state and long-term deactivation are missing. These are important parameters for industrial applications. In the present study, oscillations in the reaction traces have only been observed in the presence of a large number of faceted particles (Figure 2 and Figures S9 and S10). During the prevailing of oscillations, no morphological changes were observed (Video S7). In contrary to the pioneering study, ${ }^{21}$ in which the occurrence of surface facets was observed in the high activity regime, morphological transformations appeared to be present in our study only in the low activity regime (Figure 1). The possibility of disentangling different interactions between reactants and catalysts over the entire range of catalytic conversion and for multiple cycles while being able to separate morphological transformations (low activity) from structural changes (high activity) during a catalytic reaction have not been reported before. In addition, differentiation of chemical dynamics proves that restructuring mechanisms that have been derived in $\mathrm{CO}$ oxidation experiments over polycrystalline systems at low pressure ${ }^{41,42}$ can be transferred to the high pressure site of the reaction. This novel knowledge will prospectively allow to understand heterogeneous catalysis in greater detail and provides deeper insights into how the structure relates to the function. An in-depth discussion of the observed phenomena is given below.

3.2. Morphological Changes. In our study, cycling experiments revealed the formation of faceted surfaces of the Pt NPs, which are terminated by low index planes (Figure 2 and Figures S5-S7). This increased faceting was accompanied by a steady decay of the catalytic activity and an increase in the ignition temperature with each cycle (Figures 1 and $2 \mathrm{e}$ and Figures S8-S10). These observations are in agreement with previous studies claiming that surface facets that correspond to low index planes of NPs are less active than high index surfaces. ${ }^{43}$ The same report suggested that face-centered cubic (fcc) metal NPs terminated by open surfaces exhibit better catalytic activity than metal NPs that exhibit low index surfaces as they are characterized by a high density of atomic steps and kinks. Steps and kinks are generally discussed as the origin of high activity of Pt NPs. ${ }^{44}$ These surfaces are known to be more active compared to densely packed flat surfaces for a range of different catalytic reactions, which have been visualized by high-resolution TEM imaging outside reaction conditions. ${ }^{43,45-49}$ The observed morphological transformations may stem from surface energy minimization at solid/gas interfaces as a consequence of chemical potential gradients close to the sample during reaction. The effect of surface energy minimization can be observed by the formation of equilibrated faceted Pt NPs with exposed surfaces of the lowest surface energy $\gamma_{\{111\}}<\gamma_{\{100\}}<\gamma_{\{110\}}{ }^{43,50-53}$ that was initialized during the second cycle and became slightly more pronounced after the third cycle (Figure 2). In addition, the sequence of observed morphological transformations suggests that they require the presence of a chemical potential gradient that can be triggered not only by a temperature change alone. It was observed that morphological changes were absent as soon as the partial pressures are equilibrated despite the fact that the temperature had been increasing further. In addition, the morphological changes were found to be thermodynamically controlled and they eventually appeared to lead to deactivation (Figure 2 and Figures S8b to S10b).

In the second and third cycle, oscillations of the reaction rate were observed at the transition from morphological transformation to structural dynamics. These reaction rate oscillations can lead to rapid heat releases or pressure increases in the system. They could be caused by structural modifications of the active state that require the existence of the flat surfaces to accommodate excess of one of the reactants. This would inhibit a steady conversion of the reactants. Therefore, the formation of stable surface facets should be minimized to avoid deactivation and the potentially damaging bursts of heat associated with the oscillations of the reaction rate.

3.3. Structural Changes. A potential cause for the observed changes of the shape of the reflections in the high activity regime could be the migration of atoms to interstitial sites (Figures 3 and 4 and Figures S8-S10). The diffusion of oxygen (or carbon) into the subsurface and bulk of Pt NPs and the formation of vacancies in the lattice is the most likely explanation. Subsurface diffusion, for instance, of reactive species is common in heterogeneously catalyzed reactions over metal nanoparticles and influence the catalytic performance. $^{54,55}$ Previous studies using in situ X-ray photoelectron spectroscopy (XPS), ${ }^{14}$ surface-sensitive XRD, ${ }^{13}$ X-ray absorption spectroscopy (XAS), ${ }^{15-17}$ and scanning tunneling microscopy $(\mathrm{STM})^{18,19}$ showed that $\mathrm{Pt}$ oxide can be formed at the surface and subsurface during $\mathrm{CO}$ oxidation with different implications on the catalytic activity (see Table S2 for the results from the literature). Furthermore, the observed broadening of the reflections indicate a decrease in coherent scattering domains and therefore a decrease in long-range order within the bulk structure of Pt NPs (Figure 4a,b). The subsurface and bulk chemistry can also be explained by the observed loss of bulk structural ordering (see reflection broadening in Figures $3 \mathrm{~g}-\mathrm{i}$ and $4 \mathrm{a}, \mathrm{b}$ ) from a pure Pt metal phase in the high activity regimes (Figure la and Figures S8-S10). Thus, the appearance of additional shoulders in the electron diffraction pattern for reflections that correspond to the (111), (200), (220), and (311) lattice planes could be due to the diffusion of oxygen through the crystal planes of $\mathrm{Pt}$ atoms, which can create disorder in the structure (Figures 3 and 4 and Figures S8 to S10).

The structural changes may predominantly be caused by the reaction environment rather than by thermal effects alone. This conclusion could be derived from the following observations: (i) Nonlinear fluctuations of the position of the reflections with temperature (Figure 4), (ii) the partial reversibility of the changes of the high index reflections, and (iii) the irreversible broadening of the reflections. Thermal effects alone would cause global, nonselective changes in the SAED pattern. Moreover, if the observed structural changes would have been caused by thermal treatments, then the diffraction patterns of the pristine Pt NPs that were measured in synthetic air at 400 ${ }^{\circ} \mathrm{C}$ (Figure $3 \mathrm{~g}$ and Figure S1) and the sample measured after the ignition point in the first cycle (Figure 3i) should be 
identical. However, this is not the case. In addition, no changes were observed when comparing the pristine sample at $400{ }^{\circ} \mathrm{C}$ and the sample at $250{ }^{\circ} \mathrm{C}$ at reaction conditions in the first cycle (Figure S3).

The ability to simultaneously record reflections that correspond to low and high index planes combined with high spatial and temporal resolution are important advantages of SAED compared to XRD (see the Supporting Information for more information). Electrons interact much stronger with atoms in the crystals than X-rays. Therefore, they produce stronger reflection intensities (Figures S13 and S14). In addition, due to the very small wavelength of the electrons $(\lambda=$ $1.96 \mathrm{pm}$ at $300 \mathrm{kV}$ acceleration voltage), the radius of the Ewald sphere is large with respect to a lattice constant and can be considered flat (Figure S15). Hence, in electron diffraction experiments, the information of low and high index planes can be recorded simultaneously and with sufficient signal-to-noise ratio even at millisecond time scales. ${ }^{56}$ This combination of high temporal and spatial resolution is a crucial strength of in situ and operando TEM investigations since it allows monitoring of local changes over time that are associated with the catalytic reaction.

3.4. Disentangling Chemical Dynamics. Although morphological and structural changes are part of chemical dynamics, their origins are different (Scheme 1). Below the

Scheme 1. Chemical Dynamics Influence Different Activity Regimes of the Catalyst and Trigger Reactivity ${ }^{a}$

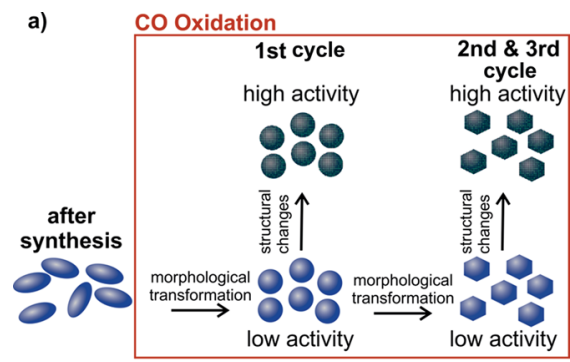

b)

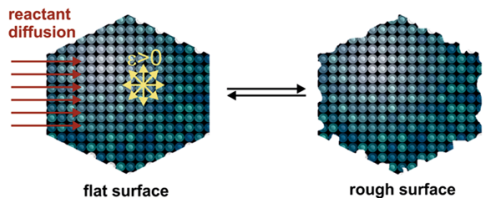

${ }^{a}$ (a) Occurrence of morphological and structural changes depends on the presence of gradients as the external trigger and appear at different activity regimes (low and high). (b) Reactant diffusion through the Pt NPs induces a frustrated phase transition, which leads to strain $(\varepsilon>0)$ inside the particle. The strain would then be relieved by the surface reconstruction.

onset temperature, where changes of the chemical potential are small and depend solely on temperature gradients, no chemical dynamics were observed (Scheme 1a). As the reaction initiated, the gas phase composition changed with temperature, leading to greater partial pressure gradients (Scheme 1a, low activity). This gradient induced morphological transformation at the surface of the catalyst, and after cycling, it led to equilibrated surface facets. At the ignition point and during steady conversion, the gas phase composition remained constant and morphological transformations became insignificant. Meanwhile, structural changes related to changes and fluctuations in the bulk structure became apparent (Scheme 1a, high activity). While morphological transformations appeared to be mostly detrimental to the catalytic activity, reactioninduced structural changes appeared to be a sign of activity and beneficial for the catalytic turnover. It is presently unclear if the structural changes and the associated stress and strain lead to the occurrence of fluctuating surface steps acting as active sites, and/or the resulting change of the electronic structure (d-band shift) affects the surface abundance of reactants and reduces the overbinding of either oxygen or $\mathrm{CO}$ and the associated site blocking.

Although primarily detrimental to the catalytic activity, morphological transformation may be an intermediary step to enable the access for reactants to diffuse through the bulk of the Pt NPs. Thereby, a high virtual pressure of a reactant could be created, which could initiate the subduction of atoms into the bulk. In this way, the flattening of the surface indirectly would cause stabilization of high active states by preparing for the structural changes (Scheme 1b). Thus, morphological transformations would be needed in a balanced form.

During reactant diffusion, the system aims to move to energetically more favorable states. However, in the case of exothermic $\mathrm{CO}$ oxidation, a high energy barrier that separates the two phases, for example, metal and oxide, inhibits the completion of this phase transition. When the energy barrier to realize a complete phase transition is too high, the system keeps fluctuating between these two chemical states in a situation that has been coined as frustrated phase transition. ${ }^{7}$ In the present case, the formation of a platinum substoichiometric oxide or a solid solution of oxygen or carbon in the bare metal could be the target phases of the attempted phase transition. Furthermore, the loss of long-range ordering (Figure 4a,b) is part of the preparation of the system to change its phase with the energy needed for reducing the translational ordering stemming from the ongoing $\mathrm{CO}$ oxidation. These frustrated phase transitions induce strain in the NPs, which can be relieved by roughening of flat surface facets on the atomic scale. In its nonequilibrated state, this surface roughening causes a sudden increase in reactivity, which is reflected by the occurrence of oscillations in the second and third cycle (Figures S9 and S10). Once in an equilibrated state it then leads to steady conversion. Thus, we attribute the origin of the oscillatory behavior in the MS traces to surface reconstructions ${ }^{19}$ or roughening of equilibrated surface facets that depend on the degree of surface coverage rather than on surface refaceting as previously stated. ${ }^{21}$

\section{CONCLUSIONS}

In conclusion, time-resolved operando TEM to study $\mathrm{CO}$ oxidation over Pt NPs revealed the dual nature of chemical dynamics in relation to catalysis as the entire range of catalytic conversion was investigated. These chemical dynamics consist of either morphological transformations or structural changes. Especially, the former were found to depend on the presence of chemical potential gradients. Morphological transformations were found to lead to the deactivation of the catalyst by forming particles with equilibrated surface facets. In contrast, structural changes, potentially based on frustrated phase transition, were found to be beneficial for the catalytic turnover. These results also suggest that commonly investigated idealized model systems with equilibrated surfaces lead to lower activity compared to high energy surfaces.

In addition, we have shown the power of operando TEM, which can provide important insights into temporally resolved 
structural and morphological changes of catalysts under relevant reaction conditions. SAED analysis has been shown to be a powerful tool to resolve changes in the structure of a crystal during catalytic reactions and to correlate them to activity. Hence, we showed that it is possible to directly image and analyze the local structure, to correlate it to the catalytic function, and to extract from these visual observable relevant descriptors of catalytic processes.

\section{MATERIALS AND METHODS}

5.1. In situ Pt NP Preparation. As described previously, ${ }^{21}$ Pt NPs were formed in situ inside the MEMS-based nanoreactor. The decomposition of the tetraamineplatinum(II) nitrate precursor was monitored online by TEM imaging and SAED to follow the formation of phase-pure Pt NPs. As indicated in Figures S1, phase-pure Pt NPs had been formed after dwelling the precursor sample for $3 \mathrm{~h}$ at $400{ }^{\circ} \mathrm{C}$ in synthetic air (temperature ramp, $5{ }^{\circ} \mathrm{C} / \mathrm{min}$; pressure, 720 mbar; flow rate, $20 \mu \mathrm{L} / \mathrm{min}$; gas feed, $20 \% \mathrm{O}_{2}$ in $\mathrm{He}$ ). All Pt NPs exhibited nonequilibrated surfaces. Agglomeration of $\mathrm{Pt}$ NPs has not been observed. However, some caution has to be applied when interpreting the TEM images since the electron micrographs were acquired at the lower end of TEM magnification and, by their very nature, conventional electron micrographs resemble two-dimensional (2D) projections of 3D systems. A detailed description of the decomposition process can be found in Figures S1 and the related text.

5.2. Operando Electron Microscopy. The homebuilt operando TEM setup consists of a gas feeding and analysis unit that is equipped with a quadrupole (Q)MS for gas analysis, which allows for online conversion detection. The setup is compatible with conventional, commercially available MEMSbased gas cell TEM holders. The specifications of the setup are a large pressure range, a fast gas exchange, large available range of flow rates from $\mu \mathrm{L} / \mathrm{min}$ to $\mathrm{mL} / \mathrm{min}$, exchangeable diameters of the inlet and outlet tubes, and very low detection limit for MS. The detailed technical description and specifications of the homebuilt operando TEM setup, including how $\mathrm{Ni}$ contamination can be avoided during $\mathrm{CO}$ oxidation, are described elsewhere. ${ }^{31}$

Imaging of the Pt NPs during the catalytic reaction was performed on a Cs-corrected FEI TITAN 80-300 at $300 \mathrm{kV}$ equipped with a GATAN UltraScan 1000XP camera. During the experiment, the electron dose rate was kept below $30 \mathrm{e} / \AA^{2} \mathrm{~s}$ at all times. Since the effect of the electron beam can never be totally excluded in EM studies, it was deemed important to always consider results comparatively and not in isolation. The findings described above withstand this criterion: during low catalytic activity, the acquired series of the TEM image (Videos S1 and S2) showed more significant changes of the morphology of the particles than in the high activity regime or at "full" conversion (Videos S3 and S4). As the morphological behavior in different catalytic regimes was found to be different depending on the catalytic cycle, the effect of the electron beam on the morphology should not play a role. Otherwise, the same changes would be observed in all regimes. This specific dose rate was chosen since several studies found it to be the safe limit below which sample damage due to electron-gas interactions has been found to be negligible and below the detection limit. ${ }^{57-59}$ In addition, the observed morphological transformations are in line with previous quasi in situ TEM results. ${ }^{32}$ As this technique decouples analysis and catalysis, the influence of the electron beam can be reduced to a negligible minimum. For the highresolution imaging of catalyst NPs, the electron dose rate used was below $1000 \mathrm{e} / \AA^{2}$ s. These images were only used to define the termination of the NPs and were always compared to images that were acquired at lower dose rates (below $30 \mathrm{e} /$ $\AA^{2} \mathrm{~s}$ ). The operando experiments were performed with the commercially available DENSsolutions climate holder. SAED patterns were recorded from an area of $0.7 \mu \mathrm{m}^{2}$, including between 100 and 150 nanoparticles each.

5.3. Image Processing. For the data analysis and image processing, DigitalMicrograph and ImageJ were used. Image stacks and their alignments were performed using ImageJ. For the diffraction pattern analysis, averaged radial profiles of integrated SAED pattern series were extracted using PASAD, a plugin for DigitalMicrograph. Image and SAED series were acquired with acquisition times of $0.5 \mathrm{~s}$, every $3-5 \mathrm{~s}$ in selected temperature ranges with a temperature ramp of $1{ }^{\circ} \mathrm{C} / \mathrm{min}$. Between image acquisitions, the pre-specimen shutter was used to further reduce the exposure of the sample to the electron beam. Image series were processed with ImageJ using noise cancellation (Figure S16). Variance and Gaussian blur filters and Z-stack projection plugin were used to determine the standard deviation of the particle shape. All image stacks were treated equally. The standard deviation (STD) was measured between image frames and summed to obtain maps of the standard deviation. The average perimeter changes between image frames were obtained by Gaussian blur filter and analyze particle plugin in ImageJ.

5.4. CO Oxidation and Evaluation of the Catalytic Data. For the detection of reactants and products, a QMS 220 PrismaPlus from Pfeiffer 1 to $100 \mathrm{amu}$ was used. CO oxidation was performed in three catalytic cycles under the following conditions: (i) gas feed, $\mathrm{CO}: \mathrm{O}_{2}: \mathrm{He}=1: 5: 19$; flow rate, $20 \mu \mathrm{L} /$ min; pressure, 700 mbar; temperature ramp from RT to 500 ${ }^{\circ} \mathrm{C}, 1{ }^{\circ} \mathrm{C} / \mathrm{min}$, which was followed by isothermal treatment at $500{ }^{\circ} \mathrm{C}$ for $1 \mathrm{~h}$ and subsequently cooled to $400{ }^{\circ} \mathrm{C}, 1{ }^{\circ} \mathrm{C} / \mathrm{min}$. (ii) Gas feed: $\mathrm{CO}: \mathrm{O}_{2}: \mathrm{He}=1: 5: 19$; flow rate, $20 \mu \mathrm{L} / \mathrm{min}$; pressure, 700 mbar; temperature ramp from 250 to $460{ }^{\circ} \mathrm{C}, 1$ ${ }^{\circ} \mathrm{C} / \mathrm{min}$. The reaction was kept overnight at $450{ }^{\circ} \mathrm{C}$ and cooled to $200{ }^{\circ} \mathrm{C}\left(5{ }^{\circ} \mathrm{C} / \mathrm{min}\right)$. (iii) Gas feed: $\mathrm{CO}: \mathrm{O}_{2}: \mathrm{He}=1: 5: 19$; flow rate, $20 \mu \mathrm{L} / \mathrm{min}$; pressure, $700 \mathrm{mbar}$; temperature ramp from 200 to $500{ }^{\circ} \mathrm{C}, 1{ }^{\circ} \mathrm{C} / \mathrm{min}$. The reaction was continued overnight at $500{ }^{\circ} \mathrm{C}$ overnight and subsequently cooled to RT $\left(10^{\circ} \mathrm{C} / \mathrm{min}\right)$.

The QMS was calibrated with air, and the error in the measurements of the air composition was $5 \%\left(\mathrm{~N}_{2}, \mathrm{O}_{2}, \mathrm{H}_{2} \mathrm{O}\right.$, $\mathrm{CO}_{2}$, and $\mathrm{Ar}$ ). Ion currents of the measured signals were converted into partial pressures of each gas involved in the reaction. The conversion of $\mathrm{CO}$ was calculated using the equation $\left(P_{\mathrm{CO}}(\mathrm{T}) / P_{\mathrm{CO}}(\mathrm{RT})\right) \times 100 \%$ where $P_{\mathrm{CO}}(\mathrm{RT})$ is the partial pressure of $\mathrm{CO}$ at $\mathrm{RT}$ and $P_{\mathrm{CO}}(\mathrm{T})$ is the partial pressure at the set temperature.

5.5. In Situ XRD Analysis. For XRD analysis, $100 \mathrm{mg}$ of the tetraamineplatinum(II) nitrate (Sigma-Aldrich) precursor were decomposed at $400{ }^{\circ} \mathrm{C}$ for $3 \mathrm{~h}$ in a muffle furnace in ambient air. The in situ XRD data was collected on a STOE Theta/theta X-ray diffractometer $\left(\mathrm{Cu} \mathrm{K} \mathrm{K}_{\alpha 1}+2\right.$ radiation, secondary graphite monochromator, scintillation counter) equipped with an Anton Paar XRK 900 in situ reactor chamber. The gas feed was mixed by means of Bronkhorst mass flow controllers using helium as an inert balance gas at a total flow rate of $100 \mathrm{~mL} / \mathrm{min}$. The effluent gas composition was monitored with a Pfeiffer OmniStar quadrupole mass 
spectrometer. XRD scans at elevated temperatures were performed in the range of $25-90^{\circ} 2 \theta$ with a step size of $0.02^{\circ}$ and a counting time of $2 \mathrm{~s} / \mathrm{step}(50 \mathrm{~min} / \mathrm{scan})$. RT measurements before, between, and after the temperature programs were always performed twice, with 2 and $10 \mathrm{~s} / \mathrm{step}$, to achieve comparability with the high-temperature data and to obtain a better signal-to-noise ratio, respectively. The sample was pretreated in $20 \% \mathrm{O}_{2}$ in $\mathrm{He}$ by heating it to $400{ }^{\circ} \mathrm{C}$ at 5 ${ }^{\circ} \mathrm{C} / \mathrm{min}$, holding the temperature for $3 \mathrm{~h}$ (including three XRD scans), and then cooled to RT at $5{ }^{\circ} \mathrm{C} / \mathrm{min}$. The $\mathrm{CO}$ oxidation reaction was performed with gas feed: $\mathrm{CO}: \mathrm{O}_{2}=1: 5$. All heating and cooling ramps were done at $1{ }^{\circ} \mathrm{C} / \mathrm{min}$ with isothermal XRD measurements at 200, 250, 300, 350, 380, 390, 400,450 , and $500{ }^{\circ} \mathrm{C}$.

\section{ASSOCIATED CONTENT}

\section{SI Supporting Information}

The Supporting Information is available free of charge at https://pubs.acs.org/doi/10.1021/acscatal.9b03692.

Pt NP formation, calorimetric data, isothermal treatment at $500{ }^{\circ} \mathrm{C}$ (first cycle), blank measurements of the conversion, morphological evolution during the second cycle, morphological evolution during the third cycle, high-resolution TEM imaging of Pt NPs over three catalytic cycles, catalytic cycling and electron diffraction, calorimetric data associated to oscillations, the effect of cooling, in situ XRD study, previous operando measurements of $\mathrm{CO}$ oxidation at elevated pressures, comparison of ED and XRD, and denoising of TEM images in the Image software (PDF)

Videos showing the morphological transformations of $\mathrm{Pt}$ NP (ZIP)

\section{AUTHOR INFORMATION}

\section{Corresponding Author}

Thomas Lunkenbein - Fritz-Haber-Institut der Max-PlanckGesellschaft, 14195 Berlin, Germany; 이이. ord.org/0000-00028957-4216; Email: lunkenbein@fhi-berlin.mpg.de

\section{Authors}

Milivoj Plodinec - Fritz-Haber-Institut der Max-Planck-

Gesellschaft, 14195 Berlin, Germany

Hannah C. Nerl - Fritz-Haber-Institut der Max-PlanckGesellschaft, 14195 Berlin, Germany; (1) orcid.org/0000-00034814-7362

Frank Girgsdies - Fritz-Haber-Institut der Max-PlanckGesellschaft, 14195 Berlin, Germany

Robert Schlögl - Fritz-Haber-Institut der Max-PlanckGesellschaft, 14195 Berlin, Germany; Max Planck Institute for Chemical Energy Conversion, 45470 Mülheim an der Ruhr, Germany

Complete contact information is available at:

https://pubs.acs.org/10.1021/acscatal.9b03692

\section{Notes}

The authors declare no competing financial interest.

\section{ACKNOWLEDGMENTS}

This work was dedicated to Prof. Dr. Dangsheng Su (19612019).

\section{REFERENCES}

(1) Kalz, K. F.; Kraehnert, R.; Dvoyashkin, M.; Dittmeyer, R.; Gläser, R.; Krewer, U.; Reuter, K.; Grunwaldt, J.-D. Future Challenges in Heterogeneous Catalysis: Understanding Catalysts under Dynamic Reaction Conditions. ChemCatChem 2017, 9, 17-29.

(2) Hansen, P. L.; Wagner, J. B.; Helveg, S.; Rostrup-Nielsen, J. R.; Clausen, B. S.; Topsøe, H. Atom-Resolved Imaging of Dynamic Shape Changes in Supported Copper Nanocrystals. Science 2002, 295, 2053-2055.

(3) Epstein, I. R.; Showalter, K. Nonlinear Chemical Dynamics: Oscillations, Patterns, and Chaos. J. Phys. Chem. 1996, 100, 1313213147.

(4) Imre, D.; Kinsey, J. L.; Sinha, A.; Krenos, J. Chemical-Dynamics Studied by Emission-Spectroscopy of Dissociating Molecules. J. Phys. Chem. 1984, 88, 3956-3964.

(5) Luntz, A. C. Chemical Dynamics of the Reactions of $\mathrm{O}(1 \mathrm{~d} 2)$ with Saturated Hydrocarbons. J. Chem. Phys. 1980, 73, 1143-1152.

(6) Sagués, F.; Epstein, I. R. Nonlinear Chemical Dynamics. Dalton Trans. 2003, 1201-1217.

(7) Schlögl, R. Heterogeneous Catalysis. Angew. Chem., Int. Ed. 2015, 54, 3465-3520.

(8) Schlögl, R. Catalysis 4.0. ChemCatChem 2017, 9, 533-541.

(9) Topsøe, H. Developments in Operando Studies and in Situ Characterization of Heterogeneous Catalysts. J. Catal. 2003, 216, 155-164.

(10) Freund, H.-J.; Meijer, G.; Scheffler, M.; Schlögl, R.; Wolf, M. Co Oxidation as a Prototypical Reaction for Heterogeneous Processes. Angew. Chem., Int. Ed. 2011, 50, 10064-10094.

(11) Herzing, A. A.; Kiely, C. J.; Carley, A. F.; Landon, P.; Hutchings, G. J. Identification of Active Gold Nanoclusters on Iron Oxide Supports for Co Oxidation. Science 2008, 321, 1331-1335.

(12) Imbihl, R.; Ertl, G. Oscillatory Kinetics in Heterogeneous Catalysis. Chem. Rev. 1995, 95, 697-733.

(13) Ackermann, M. D.; Pedersen, T. M.; Hendriksen, B. L. M.; Robach, O.; Bobaru, S. C.; Popa, I.; Quiros, C.; Kim, H.; Hammer, B.; Ferrer, S.; Frenken, J. W. M. Structure and Reactivity of Surface Oxides on $\operatorname{Pt}(110)$ During Catalytic Co Oxidation. Phys. Rev. Lett. 2005, 95, 255505.

(14) Yu, Y.; Koh, Y. E.; Lim, H.; Jeong, B.; Isegawa, K.; Kim, D.; Ueda, K.; Kondoh, H.; Mase, K.; Crumlin, E. J.; Ross, P. N., Jr.; Gallet, J.-J.; Bournel, F.; Mun, B. S. Chemical States of Surface Oxygen During Co Oxidation on $\mathrm{Pt}\left(\begin{array}{lll}1 & 1 & 0\end{array}\right)$ Surface Revealed by Ambient Pressure Xps. J. Phys.: Condens. Matter 2017, 29, 464001.

(15) Gänzler, A. M.; Casapu, M.; Boubnov, A.; Müller, O.; Conrad, S.; Lichtenberg, H.; Frahm, R.; Grunwaldt, J.-D. Operando Spatially and Time-Resolved X-Ray Absorption Spectroscopy and Infrared Thermography During Oscillatory Co Oxidation. J. Catal. 2015, 328, 216-224.

(16) Singh, J.; Nachtegaal, M.; Alayon, E. M. C.; Stötzel, J.; van Bokhoven, J. A. Dynamic Structure Changes of a Heterogeneous Catalyst within a Reactor: Oscillations in Co Oxidation over a Supported Platinum Catalyst. ChemCatChem 2010, 2, 653-657.

(17) Singh, J.; Alayon, E. M. C.; Tromp, M.; Safonova, O. V.; Glatzel, P.; Nachtegaal, M.; Frahm, R.; van Bokhoven, J. A. Generating Highly Active Partially Oxidized Platinum During Oxidation of Carbon Monoxide over Pt/Al2o3: In Situ, TimeResolved, and High-Energy-Resolution X-Ray Absorption Spectroscopy. Angew. Chem., Int.l Ed. 2008, 47, 9260-9264.

(18) van Spronsen, M. A.; Frenken, J. W. M.; Groot, I. M. N. Observing the Oxidation of Platinum. Nat. Commun. 2017, 8, 1-7.

(19) van Spronsen, M. A.; Frenken, J. W. M.; Groot, I. M. N. Surface Science under Reaction Conditions: Co Oxidation on $\mathrm{Pt}$ and $\mathrm{Pd}$ Model Catalysts. Chem. Soc. Rev. 2017, 46, 4347-4374.

(20) Rupprechter, G. Sum Frequency Generation and PolarizationModulation Infrared Reflection Absorption Spectroscopy of Functioning Model Catalysts from Ultrahigh Vacuum to Ambient Pressure. In Advances in Catalysis; Gates, B. C.; Knözinger, H., Eds. 2007; 51, 133-263. 
(21) Vendelbo, S. B.; Elkjær, C. F.; Falsig, H.; Puspitasari, I.; Dona, P.; Mele, L.; Morana, B.; Nelissen, B. J.; van Rijn, R.; Creemer, J. F.; Kooyman, P. J.; Helveg, S. Visualization of Oscillatory Behaviour of Pt Nanoparticles Catalysing Co Oxidation. Nat. Mater. 2014, 13, 884890.

(22) Chenna, S.; Crozier, P. A. Operando Transmission Electron Microscopy: A Technique for Detection of Catalysis Using Electron Energy-Loss Spectroscopy in the Transmission Electron Microscope. ACS Catal. 2012, 2, 2395-2402.

(23) Altantzis, T.; Lobato, I.; De Backer, A.; Béché, A.; Zhang, Y.; Basak, S.; Porcu, M.; Xu, Q.; Sánchez-Iglesias, A.; Liz-Marzán, L. M.; Van Tendeloo, G.; Van Aert, S.; Bals, S. Three-Dimensional Quantification of the Facet Evolution of Pt Nanoparticles in a Variable Gaseous Environment. Nano Lett. 2018, 19, 477-481.

(24) De Vrieze, J. E.; Bremmer, G. M.; Aly, M.; Navarro, V.; Thybaut, J. W.; Kooyman, P. J.; Saeys, M. Shape of Cobalt and Platinum Nanoparticles under a Co Atmosphere: A Combined in Situ Tem and Computational Catalysis Study. ACS Catal. 2019, 9, 74497456.

(25) Rupprechter, G. Surface Vibrational Spectroscopy from Ultrahigh Vacuum to Atmospheric Pressure: Adsorption and Reactions on Single Crystals and Nanoparticle Model Catalysts Monitored by Sum Frequency Generation Spectroscopy. Phys. Chem. Chem. Phys. 2001, 3, 4621-4632.

(26) Smith, D. J.; White, D.; Baird, T.; Fryer, J. R. The Characterisation of a Model Platinum/Alumina Catalyst by HighResolution Electron Microscopy. J. Catal. 1983, 81, 107-118.

(27) Wang, D.; Penner, S.; Su, D. S.; Rupprechter, G.; Hayek, K.; Schlögl, R. Silicide Formation on a Pt/Sio2 Model Catalyst Studied by Tem, Eels, and Edxs. J. Catal. 2003, 219, 434-441.

(28) Roobol, S. B.; Onderwaater, W. G.; van Spronsen, M. A.; Carla, F.; Balmes, O.; Navarro, V.; Vendelbo, S.; Kooyman, P. J.; Elkjær, C. F.; Helveg, S.; Felici, R.; Frenken, J. W. M.; Groot, I. M. N. In Situ Studies of No Reduction by $\mathrm{H} 2$ over Pt Using Surface X-Ray Diffraction and Transmission Electron Microscopy. Phys. Chem. Chem. Phys. 2017, 19, 8485-8495.

(29) Tan, S. F.; Chee, S. W.; Baraissov, Z.; Jin, H.; Tan, T. L.; Mirsaidov, U. Real-Time Imaging of Nanoscale Redox Reactions over Bimetallic Nanoparticles. Adv. Funct. Mater. 2019, 1903242.

(30) Plodinec, M.; Stotz, E.; Sandoval-Diaz, L.; Schlögl, R.; Lunkenbein, T. Multimodal Operando Electron Microscopy Approach to Study Pt Catalyst During Co Oxidation Reaction. Microsc. Microanal. 2019, 25, 1448-1449.

(31) Plodinec, M.; Nerl, H. C.; Farra, R.; Willinger, M. G.; Stotz, E.; Schlögl, R.; Lunkenbein, T., Versatile Hombuilt Gas Feed and Analysis System for Operando TEM of Catalysts at Work. Microsc. Microanal. 2020. In print.

(32) Masliuk, L.; Swoboda, M.; Algara-Siller, G.; Schlögl, R.; Lunkenbein, T. A Quasi in Situ Tem Grid Reactor for Decoupling Catalytic Gas Phase Reactions and Analysis. Ultramicroscopy 2018, 195, 121-128.

(33) Blomberg, S.; Brackmann, C.; Gustafson, J.; Aldén, M.; Lundgren, E.; Zetterberg, J. Real-Time Gas-Phase Imaging over a $\operatorname{Pd}(110)$ Catalyst During Co Oxidation by Means of Planar LaserInduced Fluorescence. ACS Catal. 2015, 5, 2028-2034.

(34) Matera, S.; Reuter, K. First-Principles Approach to Heat and Mass Transfer Effects in Model Catalyst Studies. Catal. Lett. 2009, 133, 156-159.

(35) Kooyman, P. J.; Hensen, E. J. M.; de Jong, A. M.; Niemantsverdriet, J. W.; van Veen, J. A. R. The Observation of Nanometer-Sized Entities in Sulphided Mo-Based Catalysts on Various Supports. Catal. Lett. 2001, 74, 49-53.

(36) Bremmer, G. M.; Zacharaki, E.; Sjåstad, A. O.; Navarro, V.; Frenken, J. W. M.; Kooyman, P. J. In Situ Tem Observation of the Boudouard Reaction: Multi-Layered Graphene Formation from Co on Cobalt Nanoparticles at Atmospheric Pressure. Faraday Discuss. 2017, 197, 337-351.

(37) Dembele, K.; Moldovan, S.; Hirlimann, C.; Harmel, J.; Soulantica, K.; Serp, P.; Chaudret, B.; Gay, A. S.; Maury, S.; Berliet,
A.; Fecant, A.; Ersen, O. Reactivity and Structural Evolution of Urchin-Like Co Nanostructures under Controlled Environments. J. Microsc. 2018, 269, 168-176.

(38) Roiban, L.; Li, S.; Aouine, M.; Tuel, A.; Farrusseng, D.; Epicier, T. Fast 'Operando' Electron Nanotomography. J. Microsc. 2018, 269, $117-126$.

(39) Zou, L.; Li, J.; Zakharov, D.; Stach, E. A.; Zhou, G. In Situ Atomic-Scale Imaging of the Metal/Oxide Interfacial Transformation. Nat. Commun. 2017, 8, 307.

(40) Niu, Y.; Liu, X.; Wang, Y.; Zhou, S.; Lv, Z.; Zhang, L.; Shi, W.; Li, Y.; Zhang, W.; Su, D. S.; Zhang, B. Visualizing Formation of Intermetallic Pdzn in a Palladium/Zinc Oxide Catalyst: Interfacial Fertilization by Pdhx. Angew. Chem., Int. Ed. 2019, 58, 4232-4237.

(41) Vogel, D.; Spiel, C.; Suchorski, Y.; Trinchero, A.; Schlögl, R.; Grönbeck, H.; Rupprechter, G. Local Catalytic Ignition During Co Oxidation on Low-Index Pt and Pd Surfaces: A Combined Peem, Ms, and Dft Study. Angew. Chem. Int., Ed. 2012, 51, 10041-10044.

(42) Vogel, D.; Spiel, C.; Suchorski, Y.; Urich, A.; Schlögl, R.; Rupprechter, G. Mapping the Local Reaction Kinetics by Peem: Co Oxidation on Individual (100)-Type Grains of Pt Foil. Surf. Sci. 2011, 605, 1999-2005.

(43) Tian, N.; Zhou, Z.-Y.; Sun, S.-G. Platinum Metal Catalysts of High-Index Surfaces: From Single-Crystal Planes to Electrochemically Shape-Controlled Nanoparticles. J. Phys. Chem. C 2008, 112, 1980119817.

(44) Hansen, T. K.; Hфj, M.; Hansen, B. B.; Janssens, T. V. W.; Jensen, A. D. The Effect of Pt Particle Size on the Oxidation of Co, C3h6, and No over Pt/Al2o3 for Diesel Exhaust after Treatment. Top. Catal. 2017, 60, 1333-1344.

(45) Gracia, F. J.; Bollmann, L.; Wolf, E. E.; Miller, J. T.; Kropf, A. J. In Situ Ftir, Exafs, and Activity Studies of the Effect of Crystallite Size on Silica-Supported Pt Oxidation Catalysts. J. Catal. 2003, 220, 382391.

(46) Ma, F.; Ma, S.-L.; Xu, K.-W.; Chu, P. K. Surface Stability of Platinum Nanoparticles Surrounded by High-Index Facets. J. Phys. Chem. C 2008, 112, 3247-3251.

(47) Jiang, T.; Mowbray, D. J.; Dobrin, S.; Falsig, H.; Hvolbæk, B.; Bligaard, T.; Nørskov, J. K. Trends in Co Oxidation Rates for Metal Nanoparticles and Close-Packed, Stepped, and Kinked Surfaces. J. Phys. Chem. C 2009, 113, 10548-10553.

(48) Chang, L. Y.; Barnard, A. S.; Gontard, L. C.; Dunin-Borkowski, R. E. Resolving the Structure of Active Sites on Platinum Catalytic Nanoparticles. Nano Lett. 2010, 10, 3073-3076.

(49) Zhou, Z.-Y.; Huang, Z.-Z.; Chen, D.-J.; Wang, Q.; Tian, N.; Sun, S.-G. High-Index Faceted Platinum Nanocrystals Supported on Carbon Black as Highly Efficient Catalysts for Ethanol Electrooxidation. Angew. Chem., Int. Ed. 2010, 49, 411-414.

(50) Vitos, L.; Ruban, A. V.; Skriver, H. L.; Kollár, J. The Surface Energy of Metals. Surf. Sci. 1998, 411, 186-202.

(51) Wang, Z. L. Transmission Electron Microscopy of ShapeControlled Nanocrystals and Their Assemblies. J. Phys. Chem. B 2000, 104, 1153-1175.

(52) Wen, Y.-N.; Zhang, J.-M. Surface Energy Calculation of the Fcc Metals by Using the Maeam. Solid State Commun. 2007, 144, 163167.

(53) Zhang, J.-M.; Ma, F.; Xu, K.-W. Calculation of the Surface Energy of Fcc Metals with Modified Embedded-Atom Method. Appl. Surf. Sci. 2004, 229, 34-42.

(54) Teschner, D.; Borsodi, J.; Wootsch, A.; Revay, Z.; Havecker, M.; Knop-Gericke, A.; Jackson, S. D.; Schlogl, R. The Roles of Subsurface Carbon and Hydrogen in Palladium-Catalyzed Alkyne Hydrogenation. Science 2008, 320, 86-89.

(55) Rocha, T. C. R.; Oestereich, A.; Demidov, D. V.; Hävecker, M.; Zafeiratos, S.; Weinberg, G.; Bukhtiyarov, V. I.; Knop-Gericke, A.; Schlögl, R. The Silver-Oxygen System in Catalysis: New Insights by near Ambient Pressure X-Ray Photoelectron Spectroscopy. Phys. Chem. Chem. Phys. 2012, 14, 4554-4564.

(56) Yu, J.; Yuan, W.; Yang, H.; Xu, Q.; Wang, Y.; Zhang, Z. Fast Gas-Solid Reaction Kinetics of Nanoparticles Unveiled by Milli- 
second in Situ Electron Diffraction at Ambient Pressure. Angew. Chem., Int. Ed. 2018, 130, 11514-11518.

(57) Kooyman, P. J., Development of Operando Transmission Electron Microscopy. In Operando Research in Heterogeneous Catalysis, Frenken, J.; Groot, I., Eds. Springer International Publishing: Cham, 2017; 111-129, DOI: 10.1007/978-3-319-44439-0_5.

(58) Taheri, M. L.; Stach, E. A.; Arslan, I.; Crozier, P. A.; Kabius, B. C.; LaGrange, T.; Minor, A. M.; Takeda, S.; Tanase, M.; Wagner, J. B.; Sharma, R. Current Status and Future Directions for in Situ Transmission Electron Microscopy. Ultramicroscopy 2016, 170, 8695.

(59) Wagner, J. B.; Beleggia, M., Gas-Electron Interaction in the Etem. In Controlled Atmosphere Transmission Electron Microscopy: Principles and Practice, Hansen, T. W.; Wagner, J. B., Eds. Springer International Publishing: Cham, 2016; 63-94. 